\title{
NEWS FROM THE INTERNATIONAL SOCIETY OF BIORHEOLOGY
}

As you all know from the contents of this issue, the triennial meeting of the International Society of Biorheology is being held in Tokyo this August. Professor Eiichi Fukada and his committee are planning an extremely interesting and timely program. Over 170 abstracts have been accepted for presentation at the Congress, many from biorheologists who have not previously attended our meeting. Participants will therefore be able to meet and exchange ideas with investigators who they may not have had the opportunity of meeting before. We hope that as many of you as possible will be able to attend the Fourth Congress and make it as successful as the La Jolla meeting in 1978 .

A high point of the Congress will be the awarding of the Poiseuille Medal to Professor Alexander Silberberg of the Weizmann Institute of Science. This gold medal, commemorating the great French physician and physiologist Poiseuille, who is recognized as the first hemorheologist, is being presented to Professor Silberberg for his outstanding contributions to the field of biorheology particularly in the areas of suspension rheology, blood viscoelasticity and the behaviour of macromolecules at interfaces. Professor Silberberg served as President of our Society from 1972 to 1978 and has continued to act on the Council as Past-president, Liaison Officer to the International Union of Pure and Applied Biophysics, Liaison Officer to the International Society of Rheology and, most recently, as Co-Editor-in-Chief of this journal. I am sure all the members of our Society and the community of biorheologists as a whole join me in offering Professor Silberberg our heartiest congratulations and best wishes.

The regular business meeting of the Society will also be held during the Congress, at which time a number of issues important to members of the international biorheology community will be discussed. One such question centers around the formal relationship, if any, between the International Society of Biorheology and other regional or national societies in areas related to biorheological studies. A second area to be discussed will be the relationship between our Society and the International Union of Pure and Applied Biophysics (IUPAB). Because our Congress and that of IUPAB coincide there is less attendance by our members at the Biophysics Congress than might otherwise be the case. Ways in which this situation might be remedied will therefore be addressed.

Since the La Jolla Congress the national location of the Fifth Congress of Biorheology has been selected and a Chairman for the meeting elected. Professor Siegfried Witte has agreed to organize the Fifth Congress in the Federal Republic of Germany. While the dates and exact site have not yet been set, I am sure the selection will contribute to yet another successful meeting. Certainly the very active European community of biorheologists will provide a solid foundation on which to develop the Congress. Further information regarding this meeting will be published in Biorheology as it becomes available.

See you in Tokyo:

\author{
D.E. Brooks \\ Secretary-General \\ International Society of Biorheology \\ Department of Pathology \\ University of British Columbia \\ Vancouver, Canada V6T 1W5
}

